\title{
Uma experiência didática com jogos educativos no ensino de ciências
}

\section{A didactical experience with educational games in teaching science}

\author{
Juliana Yporti de Sena ${ }^{1}$ \\ Julianays21@yahoo.com.br \\ Zenaide de Fátima Dante Correia Rocha ${ }^{2}$ \\ Zenaide.dante@bol.com.br
}

\section{Resumo}

Este trabalho analisa uma experiência didática no ensino de ciências por meio de jogos educativos, em vista das dificuldades dos estudantes na compreensão de conceitos científicos trabalhados em aulas convencionais. De natureza qualitativa, a pesquisa tem o viés de pesquisa-ação. $O$ objeto de estudo está na produção e aplicação de jogos educativos no ensino de ciências, numa escola particular de Londrina-PR, com a participação de cinco estudantes do sétimo ano e sete estudantes do nono ano do ensino fundamental. O potencial didático desse recurso foi analisado à luz do referencial teórico da pedagogia histórico-crítica. Com a aplicação dos jogos, houve uma melhora significativa do processo de aprendizagem dos conteúdos, uma ferramenta potencial para educação em ciências.

Palavras-chave: Jogos educativos, Ensino de ciências, Aprendizagem significativa, Recurso didático, Dinâmica de ensino

\section{Abstract}

This research analyzes a science teaching experience through educational games, considering that the students have difficulty with scientific concepts and with conventional methodologies. This research is based on a qualitative approach and it is characterized as an action research. The object of study is focused on the production and application of educational games in science classes, in a private school in the city of Londrina-PR with the participation of five students from the seventh grade and seven students from ninth grade. The didactic potential of this activity was based on the historical-critical theory. The use of games in class resulted in a remarkable improvement in the learning process, in other words, the games are potential tools for science education.

Keywords: Education games, Science teaching, Meaningful learning, Didactic resource, Teaching dynamic

\footnotetext{
${ }^{1}$ Mestranda em Ensino de Ciências Humanas, Sociais e da Natureza da Universidade Tecnológica Federal do Paraná, Campus Londrina.

2 Docente do Programa de Pós-graduação - Mestrado Profissional em Ensino de Ciências Humanas, Sociais e da Natureza da Universidade Tecnológica Federal do Paraná, Campus Londrina.
}

Revista Educação Online, n. 17, set-dez 2014, p. 1-13 


\section{Introdução}

A superação dos modelos tradicionais de ensino tem sido uma realidade vigente nas pesquisas em educação e contribuir para que essa mudança ocorra de maneira critica é permitir que o conhecimento surja a partir de práticas sociais, é realizar práticas pedagógicas que possibilitem mudanças sociais e não sua perpetuação (SAVIANI, 2000).

A proposta de jogos didáticos pode auxiliar o professor a tornar a aula mais interessante e conquistar a atenção dos estudantes, no sentido de viabilizar espaço para um processo de ensino e aprendizagem interativo, potencializando um ambiente mais estimulante para a resolução de problemas que demandam análise crítica e criativa (ANTUNES, 2003).

Nessa perspectiva, os jogos pedagógicos podem ser uma das ferramentas capazes de viabilizar esse ambiente de transformação para 0 aluno, já que apresenta potencial para proporcionar "o desenvolvimento de habilidades aos estudantes e ao professor no sentido de ampliar novas técnicas de ensino e aprendizagem, estimulando a ele próprio em sua prática docente" (BRASIL, 1999, p.74).

Dessa forma, o presente trabalho é um recorte de uma pesquisa, cuja intenção foi produzir e aplicar jogos educativos como recurso didático no ensino de ciências para os anos finais do ensino fundamental. Especificamente, tem como objetivo apresentar material didático para o ensino de ciências, a fim de disponibilizá-lo aos professores, para que possam dinamizar o planejamento dos conteúdos curriculares e estimular o interesse dos estudantes pela ciência.

\section{Jogos lúdicos e suas contribuições pedagógicas no ensino}

A passagem do ensino, da mera forma de transmissão de conhecimento para um processo dialógico, interativo e estimulante em busca de uma aprendizagem significativa passou a ser um desafio para os educadores. Saviani (2000, p.89) acredita que "a escola tem o papel de possibilitar o acesso das novas gerações ao mundo do saber sistematizado, do saber metódico, científico". Nessa condição, a 
escola é o lugar privilegiado para a alfabetização e divulgação do conhecimento científico e, portanto, necessita organizar processos, descobrir formas adequadas a essa finalidade.

Essa transição de um ensino pautado em pedagogias tradicionais, que visam a valorizar atribuições de mercado, como a pedagogia tecnicista, baseada no professor como centro do conhecimento, precisa ser reformulada (SAVIANI, 2000).

Nesse contexto, os jogos surgem como uma ferramenta potencializadora da ação pedagógica. Como cita Antunes (2003), "o jogo o ajuda a construir suas novas descobertas, desenvolve e enriquece sua personalidade e simboliza um instrumento pedagógico que leva ao professor a condição de condutor, estimulador e avaliador da aprendizagem" (p. 36).

Para que o jogo seja considerado pedagógico e não apenas lúdico, é necessário que o professor tenha o domínio do conteúdo, o domínio da técnica de ensino e o manejo da relação estabelecida entre os sujeitos participantes. Jogos ou brinquedos pedagógicos são desenvolvidos com a intenção explícita de provocar uma aprendizagem significativa, estimular a construção de um novo conhecimento e, principalmente, despertar o desenvolvimento de uma habilidade operatória, uma aptidão ou capacidade cognitiva e apreciativa específica, que possibilita a compreensão e a intervenção do indivíduo nos fenômenos sociais e culturais e que o ajude a construir conexões (ANTUNES, 2003).

Além disso, os jogos pedagógicos podem ser relacionados com tantas outras técnicas que possibilitam uma ampla rede de ferramentas ao professor. No trabalho desenvolvido por Celso Antunes (2003) sobre técnicas pedagógicas, ele elenca itens positivos a respeito da dinâmica de grupo, que pode ser observada na aplicação de jogos, tais como um estudo formativo, em que os estudantes passam a ter autonomia nesse processo interativo, saindo da convencional aula expositiva.

Permite também avaliar diversos progressos de aprendizagem do aluno, possibilitando ao professor a análise de outros parâmetros de desenvolvimento do estudante. Antunes (1974) acredita que o jogo estimula o desenvolvimento da personalidade, pois constrói situações em que o estudante: "trabalha, pesquisa, discute, constrói, conclui e raciocina" (p.19), além de oportunizar uma observação mais sutil do processo de desenvolvimento e aprendizagem desses estudantes, por 
parte do professor.

Piaget (1975), também ressalta o importante papel que os jogos produzem sobre o aspecto cognitivo:

Se $o$ ato de inteligência culmina num equilíbrio entre assimilação e acomodação, enquanto a imitação prolonga a última por si mesma, poder-se-á dizer, inversamente, que o jogo é essencialmente assimilação, ou assimilação predominando sobre a acomodação. (p.115)

Para Chateau (1987), os jogos são sociais, por se familiarizarem com o trabalho:

[...] o jogo prepara para o trabalho, é que ele é introdutório ao grupo social. Para o grande, jogador é cumprir uma função, ter um lugar na equipe, o jogo, como o trabalho, é, por conseguinte, social. Por ele, a criança toma contato com as outras, se habitua a considerar o ponto de vista de outrem, e sair de seu egocentrismo original. O jogo é atividade de grupo. (p. 126)

Lopes (2000) relata que os jogos criam para o professor uma forma mais atrativa e motivadora para trabalhar os conteúdos e aplicar as avaliações, possibilitando ao educador alcançar diferentes objetivos. Muitos são os pesquisadores em educação a afirmar o potencial educativo dos jogos, dentre os quais destacamos Kishimoto (2003, p.23), que menciona a importância desse recurso "[...] como a aquisição de conteúdos e o desenvolvimento de habilidades e, ao tempo, o desenvolvimento integral da criança".

Para Almeida (1974), os jogos educativos podem proporcionar diversos benefícios, tais como aqueles relacionados à parte física, pois possibilitam trabalhar a psicomotricidade, sendo uma prática que consolida o desenvolvimento motor da criança e o seu envolvimento psíquico, social e afetivo nas atividades.

[...] sob o aspecto mental, os jogos visam a atingir o desenvolvimento da memória, da atenção, da observação, do raciocínio, da criatividade, da aquisição de hábitos ou virtudes morais, como lealdade, a bondade. Sob o ponto de vista social, os jogos visam a estimular o companheirismo, desenvolver o espírito de cooperação, o senso social e a democratização. (ALMEIDA, 1974, p. 32)

Nessa perspectiva, a presente pesquisa busca aplicar jogos educativos e verificar se as contribuições sugeridas pelos autores, tais como aguçar a criatividade, a observação, o raciocínio, entre outras habilidades se concretizam e possibilitam uma aprendizagem significativa no ensino de ciências, tornando a aula mais atrativa e interessante do ponto de vista da dinâmica interativa entre os educandos, educador 
e conhecimento científico em estudo.

\section{Metodologia}

O procedimento metodológico tem por finalidade a pesquisa qualitativa, caracterizando-se como uma pesquisa-ação. Uma pesquisa pode ser qualificada de pesquisa-ação, quando há, de fato, uma ação por parte das pessoas ou grupos implicados no problema sob observação (THIOLLENT, 1996).

Nesse contexto, a produção e aplicação de material didático desenvolvido no presente estudo apresenta um viés de pesquisa-ação, pois "com a pesquisa-ação, os pesquisadores pretendem desempenhar um papel ativo na própria realidade dos fatos observados" (THIOLLENT, 1996, p. 15).

O trabalho foi desenvolvido em uma escola particular situada no município de Londrina-PR, com duas turmas do ensino fundamental, uma do nono ano, e outra do sétimo ano, durante as aulas regulares de ciências. As aulas ocorreram separadamente em cada turma, tendo como objeto de estudo sete estudantes do nono ano, com treze anos de idade, e cinco estudantes do sétimo ano, com onze anos de idade.

A pesquisa transcorreu em dois momentos: na construção de jogos a partir da elaboração de conceitos científicos e em sua aplicação. Na construção dos jogos, que corresponde à observação de um vídeo e a leitura de um texto, foram necessárias quatro aulas, e para a aplicação, uma aula.

O primeiro teve por objetivo a elaboração dos jogos, que se iniciou mediante pesquisa acerca do tema estudado. Vale ressaltar que o planejamento do conteúdo em foco seguiu o embasamento teórico metodológico das Diretrizes Curriculares Estaduais da Educação Básica para o Ensino de Ciências (PARANÁ, 2008) que prima pela investigação historicamente contextualizada, no sentido de possibilitar que o conhecimento adquirido se torne parte integrante de saberes do indivíduo, promovendo uma mudança social (SACRISTAN, 2000 apud PARANÁ, 2008).

O conteúdo estruturante biodiversidade, que engloba diversos conteúdos específicos, foi selecionado para trabalhar a confecção dos jogos com a turma de sétimo ano, sendo que essa turma escolheu, especificamente, o conteúdo "teoria da evolução dos seres vivos". Em particular, no nono ano, foco dessa investigação, 
esse mesmo conteúdo estruturante apresentou o conteúdo básico energia, que engloba os conceitos da física.

No que tange à teoria da evolução, foram selecionados os conceitos sobre seleção natural, diferenciação entre espécies e história da viagem de Darwin. Para que esses conceitos estivessem presentes nos jogos produzidos, foi apresentado aos estudantes o vídeo Nós: os fantásticos seres vivos ${ }^{3}$, que contém trechos em desenho animado das adaptações que surgiram nas espécies, respaldando a teoria da seleção natural, trabalhando as diferenças anatômicas e fisiológicas dos grupos dos anfíbios, répteis e mamíferos. Para complementação do vídeo, foi disponibilizado um texto produzido pela professora, contendo trechos históricos da viagem de Darwin ao redor do mundo, em especial para Galápagos.

Após a leitura e a discussão do texto, junto à análise fímica, os estudantes selecionaram os termos científicos e conceitos que conseguiram identificar, para, posteriormente, representá-los por meio de figuras e conceituação descritiva.

De forma interdisciplinar, os conceitos de física foram abordados através do conteúdo de propriedades da matéria, especialmente, o conceito de densidade. Para essa etapa, foi disponibilizado material didático elaborado pela professora, que continha aspectos da história da ciência e vídeos envolvendo a temática.

O vídeo apresentado foi Arquimedes e a história do Rei Hierão ${ }^{4}$, que relata a descoberta da densidade, através das medidas volume e massa. Como material de apoio, os alunos tiveram acesso a um texto produzido pela professora, contendo situações em que pode ser aplicada fórmula da densidade, similar à situação explicitada no vídeo.

Posteriormente, foi sugerido pela professora um trabalho em grupo, no qual os estudantes definiram os conceitos da física observados no vídeo e no texto e representados em figuras e em textos descritivos sobre os conceitos.

Para a construção das figuras que referenciassem os conceitos previamente definidos pelas duplas, foi sugerida aos estudantes a atividade de pesquisa, por meio de Internet. Essas figuras deveriam conter o maior número de detalhes possíveis, permitindo que os demais colegas relacionassem a figura às definições

\footnotetext{
3 Disponível em: http://www.youtube.com/watch?v=pYbKhi5rqqs. Acesso em: 20 abril 2014. 4 Disponível em: http://www.youtube.com/watch?v=X8c3AdgMi9w. Acesso em: 20 abril 2014.
} 
conceituais produzidas.

Ainda durante a produção do jogo, em ambas as turmas, os estudantes foram separados em duplas para que pudessem relatar o que haviam identificado e observado com a leitura e a análise do vídeo e, mediante as discussões, chegarem a um consenso em relação aos conceitos trabalhados, registrando-os sinteticamente no sentido de definir tais conceitos.

Ambos os jogos foram construídos seguindo as regras e as características do jogo da memória. Dessa forma, os estudantes deveriam encontrar os conceitos apreendidos, identificando a carta que apresentava a imagem e o conceito correspondente a ela.

No segundo momento, ocorreu a aplicação dos jogos. O primeiro passo foi repassar as regras constituintes de cada jogo, quando cada estudante teria uma oportunidade para encontrar as cartas correspondentes entre si. Caso obtivesse êxito nessa ação, permaneceria no jogo com mais uma chance e, caso contrário, passaria a sua vez.

Ao final da aplicação dos jogos, foi sugerida aos estudantes a construção de um mapa conceitual, também compreendidos, segundo Moreira (2012), como "diagramas de significados, relações significativas, de hierarquias conceituais" (p.1), que buscam organizar e hierarquizar conceitos. Essa etapa serviu como diagnóstico para identificação da aprendizagem conceitual trabalhada nos jogos. Durante a prática, a professora atuou como observadora, somente mediando a atividade quando os estudantes apresentavam dúvida ou buscavam auxílio.

\section{A experiência didática: resultados e discussão}

A experiência de ensino, que propusera a elaboração e o manejo de jogos durante o processo de ensino e aprendizagem de conceitos científicos pelos estudantes do sétimo ano e do nono ano do Ensino Fundamental II, buscou implementar uma inovação na prática pedagógica como forma alternativa para o ensino e a aprendizagem de ciências.

O objetivo das atividades lúdicas, como os jogos é criar um ambiente em que o estudante aprenda o conteúdo de maneira prazerosa, diferente das aulas convencionais, ainda muito expositivas e pouco dialógicas. 
Essa abordagem metodológica, bem como sua importância, tem sido muito discutida e é consenso entre os pesquisadores e educadores na área; porém, a o uso dessa metodologia na prática pedagógica é ainda muito tímida. Acreditando na possibilidade de tornar essa experiência didática investigada uma prática comum entre os docentes, vale ressaltar que os estudantes, sujeitos dessa pesquisa, puderam refletir sobre os conteúdos abordados, pois os jogos criam um ambiente de disputa, diversão e criatividade, proporcionando a eles a interação com o conhecimento cientffico, com seus pares e com o professor. Em outras palavras, é possível inferir que esse ambiente educativo é necessário para que os estudantes adquiram noções básicas dos conceitos trabalhados e se familiarizem com os termos dos conteúdos, para que, durante a aplicação dos jogos, sintam-se confiantes na superação dos obstáculos que esse tipo de atividade proporciona em sua relação com o conhecimento, com seus pares e consigo mesmo.

A figura (1) ilustra a apresentação do conteúdo "Teoria da evolução", e a figura (2) retrata o conceito da física sobre densidade, cuja proposta era criar uma situação, na qual o aluno relacionasse a figura com um determinado conceito aprendido. Para ambas as turmas, os procedimentos de construção e aplicação dos jogos seguiram os mesmos padrões.

Após a discussão dos conceitos e termos científicos trabalhados acerca do tema em estudo pelos estudantes mediados pela professora, ela thes explicou as regras do jogo. Os participantes deveriam lançar o dado para sortear quem começaria o jogo; posteriormente, de forma individual, deveriam encontrar conceitos nos cartões que estavam dispostos de forma descritiva, relacionando-os com o cartão que continha a figura correspondente. O estudante que encontrasse os cartões corretos teria a oportunidade de continuar prosseguindo o jogo, mas, caso não os encontrasse, a vez passava para o próximo jogador.

Durante a realização do jogo, a professora percebeu a ansiedade dos estudantes em jogar e demonstrar sua capacidade de usar as peças quando elas fossem necessárias, então coordenou o trabalho no sentido de implicá-los na construção coletiva, o que facilitou as trocas conceituais entre eles e a argumentação durante as discussões, ações que geraram consenso na elaboração do trabalho. Um aspecto relevante nesse jogo é que sua finalização depende do 
auxílio de todos, ou seja, para atingir o objetivo final, que culminou na construção de um mapa conceitual individual, cada estudante pôde trazer sua contribuição. Contudo, vale destacar que a professora teve um papel fundamental na condução da atividade e gerenciamento do conteúdo, já que esse "manejo" Ihe proporcionou identificar o que cada estudante aprendeu ao final da utilização do jogo.

Os jogos permitem uma simulação da vida real que ainda não pode ser alcançada pela criança, começando pelo sistema de regras vinculado aos jogos. A vida social se relaciona a diversas atividades humanas, que envolvem cooperação facilmente vivenciada pelos jogos (ALMEIDA, 1974).

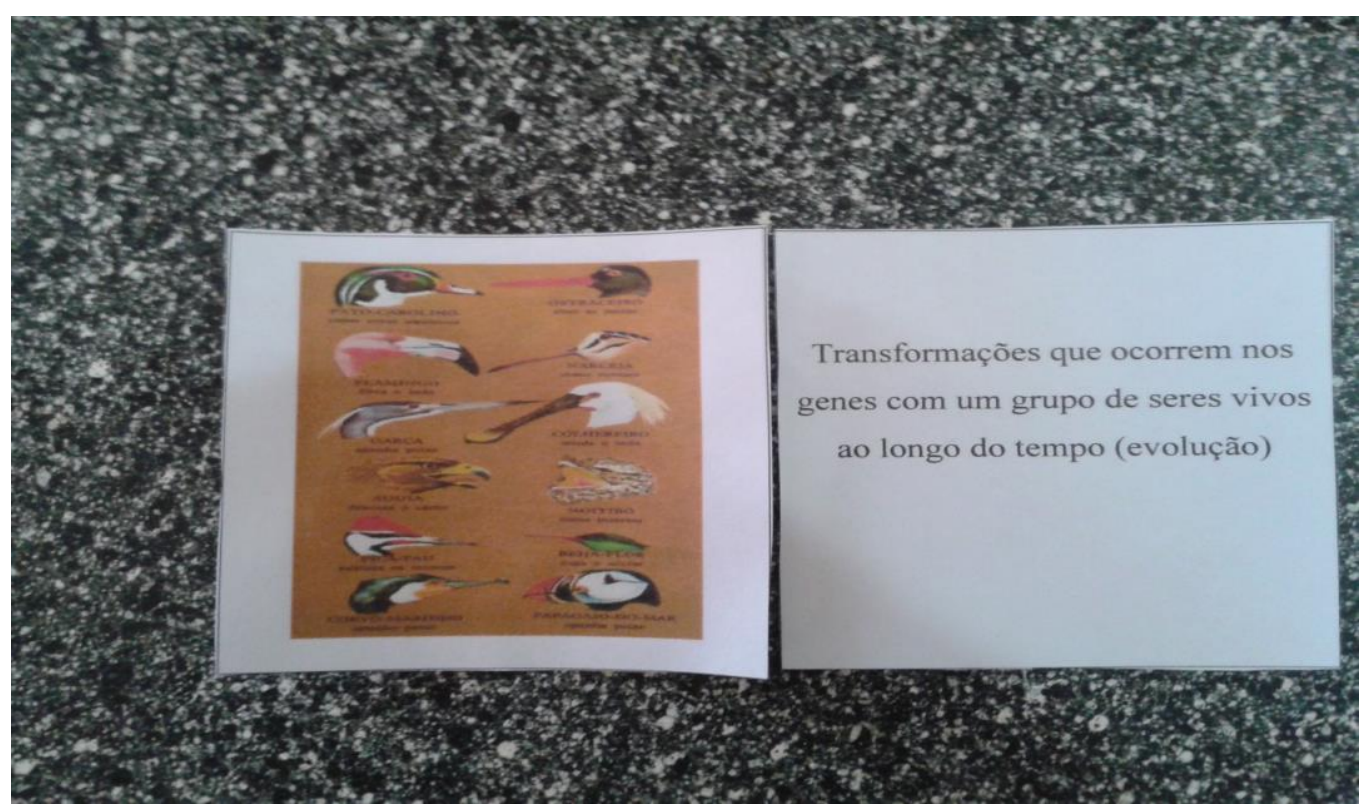

Figura (1) Jogo da memória conceitos de evolução Fonte: próprio autor

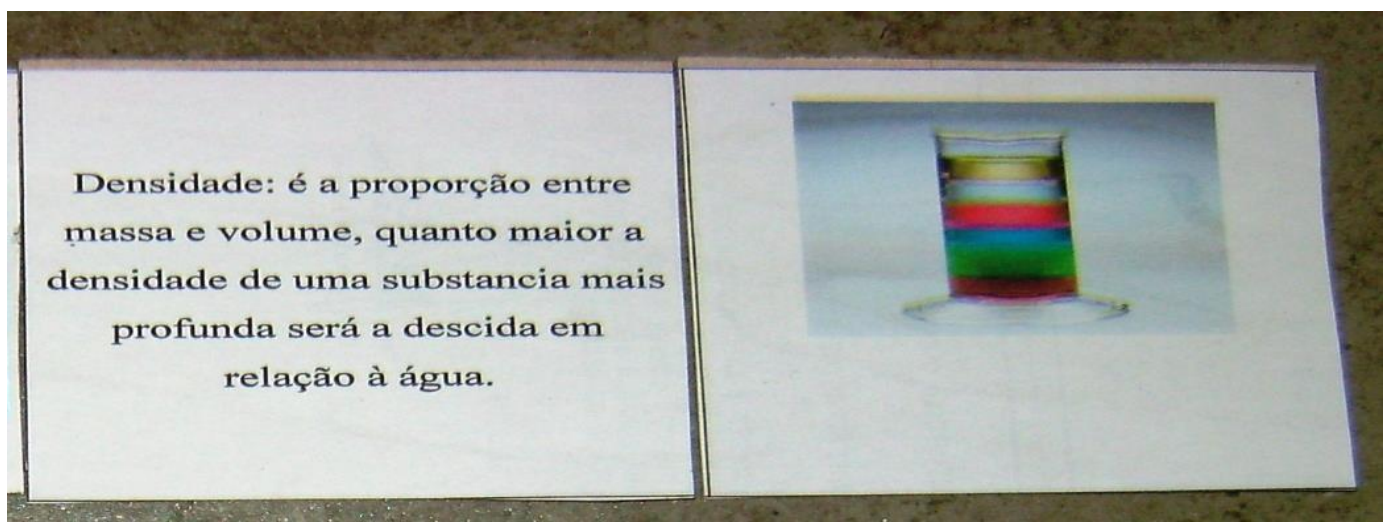

Figura (2) Jogo da memória conceitos de física Fonte: próprio autor

Revista Educação Online, n. 17, set-dez 2014, p. 1-13 
Para ambas as turmas, foram observadas situações similares, sobre a questão de aprendizagem e clima de interação durante a aplicação dos jogos.

Os estudantes atingiram o objetivo proposto para esse jogo, ao relacionarem todos os desenhos com as características da densidade, e, a cada jogada, a professora os percebia mais atentos aos detalhes de cada cartão. Ao visualizar ações bem-sucedidas de seus colegas, aqueles estudantes que não obtiveram êxito na atividade perceberam, por meio de observação e interação grupal, que seria necessário compreender os conceitos científicos envolvidos, para então associarem à determinada figura apresentada no jogo. Dessa forma, passaram a ter sucesso na resolução das questões-problema apresentadas em cada etapa do jogo. Esse resultado qualitativo se assemelha ao realizado por Lopes (2000, p.31) “[...] os resultados começaram a aparecer a cada sessão, por meio de matrizes de comportamento, o que demonstrou o quanto estavam aprendendo conteúdos, conceitos e valores".

O envolvimento constante dos estudantes, tanto na construção, quanto na aplicação dos jogos, permitiu à professora trabalhar habilidades, tais como: a criatividade, o autoconceito, a antecipação de estratégia e o raciocínio lógico, atributos já identificados por Lopes (2000) em seu trabalho. Foi possível observar também que a participação ativa durante a construção dos jogos possibilitou aos estudantes entrarem em contato com o conhecimento cientificamente elaborado e argumentarem com seus pares e com a professora a respeito dos conceitos e terminologias estudadas. A esse respeito, é relevante destacar que "utilizar o jogo na educação significa transportar para o campo do ensino-aprendizagem condições para maximizar a construção do conhecimento" (KISHIMOTO, 2001, p.37).

\section{Considerações Finais}

É possível aferir mediante a construção dos jogos e a aplicação desses nas atividades grupais, que os estudantes experienciaram uma aprendizagem significativa com relação aos conteúdos conceituais, pois, durante todo o processo de construção dos jogos, definiram e identificaram os conceitos e as terminologias que se relacionam com os conteúdos, a partir do que compreenderam. Fato que também ficou muito evidente, na construção dos mapas conceituais. 
Em relação a ações atitudinais, tais como, interesse e curiosidade por parte dos estudantes, relatos realizados pela professora, logo após a aplicação das aulas utilizando-se os jogos como recursos didáticos, revelam dentre outras, uma reflexão por ela mencionada: Durante a construção dos jogos, os estudantes demonstraram mais interesse pelos conteúdos abordados do que normalmente têm apresentado em aulas nas quais tenho optado apenas pela utilização do livro didático.

Antunes (2003, p.36) corrobora com a reflexão da professora, quando coloca que "o jogo ajuda a criança a construir suas novas descobertas, desenvolve e enriquece sua personalidade e simboliza um instrumento pedagógico que leva 0 professor à condição de condutor, estimulador e avaliador da aprendizagem".

Outro resultado em evidência é a contribuição dos jogos como atividade que possibilitam uma série de situações que não são convencionais às atividades tradicionais, como a afetividade, a manipulação de objetos, interações sociais, proporcionando a utilização de múltiplas inteligências das crianças (KISHIMOTO, 2001, p. 36).

O jogo é um método que pode ser empregado de diversas formas, o que viabiliza inúmeros níveis mentais, tais como: memória, criatividade, raciocínio lógico, concentração. Com os jogos, a criança aprende a definir valores, a formar juízos e a fazer escolhas (ALMEIDA, 1974).

Em ambas as turmas, observou-se a interação entre os estudantes, com a ressalva de que, no nono ano, a questão de disputa era algo que ocorria de forma mais acentuada comparado ao sétimo ano, fato que pode revelar ao professor as particularidades dos estudantes quanto ao manejo de diferentes problemas e potencial para construções quando trabalham em grupos. Situações como essas, proporcionadas pelos jogos, os tornam uma atividade que, além de aguçar outras habilidades pouco desenvolvidas nos estudantes, permite a experimentação da vivência grupal em situações similares àquelas trabalhadas em sala de aula, em vista de outras relações sociais, tais como o respeito às regras e os argumentos plausíveis àquele grupo social.

A oportunidade dos estudantes de serem os gestores da construção dos jogos educativos é outro ponto relevante na apropriação dos conhecimentos, pois permite autonomia no gerenciamento das ações junto ao grupo, a capacidade de 
pesquisa, interpretação e releitura de diferentes fontes de informações e, em consonância com Lopes (2000), há o potencial para trabalhar conceitos, elaborar estratégias e planejamento para a produção da atividade.

$\mathrm{Na}$ perspectiva da pedagogia histórico-crítica, os jogos aqui mencionados possibilitaram aos estudantes entrarem em contato com o conhecimento científico, despertando a curiosidade pelos conceitos, além de viabilizar a reorganização de construções equivocadas frente ao grupo.

A respeito da transformação do saber elaborado em saber escolar, afirma Saviani (1994, p.97):

Essa transformação é o processo através do qual selecionam-se, do conjunto do saber sistematizado, os elementos relevantes para o crescimento intelectual dos estudantes e organizam-se esses elementos numa forma, numa sequência tal que possibilite a sua assimilação.

Para tanto, é fundamental que o educador planeje suas aulas buscando atender aos objetivos que remetem ao processo de alfabetização científica. Dessa forma, acreditamos em um trabalho mais interativo e dialógico, proposto com vistas a uma pedagogia histórico-crítica, que, em oposição à visão de ensino por memorização e sem significado, propõe considerar a construção histórica e social desse sujeito em processo de aprendizagem e construção constante. Com este trabalho, foi possível estimular o gosto dos estudantes por aprender ciências na educação básica. Os jogos pedagógicos proporcionaram uma maneira divertida de relacionar os conceitos dos conteúdos abordados, além de despertar a criatividade e a investigação por parte dos estudantes.

Em suma, acredita-se que atividades mais dinâmicas tornam as aulas mais atrativas, contribuindo para uma mudança de atitudes, tanto de estudantes, quanto de professores, potencializando o processo de ensino e de aprendizagem.

\section{Referências bibliográficas}

ALMEIDA, P. N. Dinâmica lúdica: técnicas e jogos pedagógicos. São Paulo: Editora Loyola, 1974.

ANTUNES, C. Técnicas pedagógicas de dinâmica de grupo. São Paulo: Editora do Brasil S.A, 1974.

Jogos para a estimulação das múltiplas inteligências. Petrópolis: Editora Vozes, 2003. 
CHATEAU. J. O jogo e a criança. São Paulo: Summus, 1987.

BRASIL. Secretaria de Educação Média e Tecnologia, Ministério da Educação. Ciências da natureza, matemática e suas tecnologias. Parâmetros Curriculares Nacionais do Ensino Médio. Brasilia: MEC,SEB, 1999.

FREIRE. Paulo. Pedagogia do oprimido. Rio de Janeiro: Paz e Terra, 2005.

GASPARIN, J. L. Uma didática para a pedagogia histórico-crítica. $3^{a} e d$. Campinas: Autores Associados, 2005.

KISHIMOTO. T. M. (Org.). Jogo, brincadeira e a educação. 5ª̣ed. São Paulo: Cortez, 2001.

Learning, 2003.

O jogo e a educação infantil. São Paulo: Pioneria Thomson

LOPES. M da G. Jogos na educação: criar, fazer, jogar. 3ª̣ed. São Paulo: Cortez, 2000.

MOREIRA. A. M. Mapas conceituais e aprendizagem significativa. Porto Alegre: Revista Galáico, 1988, revisado 2012. Disponível em: $<$ http://www.if.ufrgs.br/ moreira/mapasport.pdf>. Acesso em: 22 nov. 2014.

PELIZZARI. A.et al. Teoria da Aprendizagem Significativa segundo Ausubel. Revista. PEC, v.2, n.1, p.37-42, jul. 2001-jul. 2002. Disponível em: $<$ http://scholar.google.com.br/scholar?q=teria+segundo+ausubel $>$. Acesso em: 10 jul. 2013.

PARANÁ. Secretaria de Estado da Educação do Paraná. Diretrizes Curriculares da Educação Básica Ciências. Curitiba: SEED, 2008.

PIAGET. J. A formação de símbolo na criança: imitação, jogo e sonho, imagem e representação. 2ª̂ed. Rio de Janeiro; Brasilia: Zahar, 1975.

SAVIANI. D. Pedagogia histórico-crítica: primeiras aproximações. $7^{a}$ ed. Campinas: Autores Associados, 2000.

THIOLLENT. M. Metodologia da pesquisa-ação. 7ª̣ed. São Paulo: Cortez, 1996. 